\title{
Kinetic Study of the Catalytic Pyrolysis of Oil-Containing Waste
}

\author{
Kirill Chalov, Yury Lugovoy, Yury Kosivtsov, Mikhail Sulman, Esther Sulman*, \\ Valentina Matveeva, Antonina Stepacheva \\ Department of Biotechnology and Cemistry, Tver State Technical University, \\ Afanasiy Nikitin str., 22, Tver 170026, Russia
}

Received: $13^{\text {th }}$ July 2015; Revised: 25th March 2016; Accepted: $1^{\text {st }}$ April 2016

\section{Abstract}

Basing on the experimental data the optimal parameters of the pyrolysis of heavy and residual hydrocarbons of oil were defined as follows: temperature of $500{ }^{\circ} \mathrm{C}$; catalyst of $\mathrm{CoCl}_{2}$ with the catalyst loading $5 \%$ (wt.) of the substrate weight. Under the optimal conditions the kinetic investigation of the pyrolysis process was carried out using the thermogravimetric method. According to the investigation, it was found that the activation energy of the catalytic pyrolysis of oil-containing waste decreased by $20-30 \mathrm{~kJ} / \mathrm{mol}$ in comparison to non-catalytic process. Copyright (C) 2016 BCREC GROUP. All rights reserved

Keywords: thermocatalytic processing; pyrolysis; heavy and residual hydrocarbons; metals chlorides; kinetic

How to Cite: Chalov, K., Lugovoy, Y., Kosivtsov, Y., Sulman, M., Sulman, E., Matveeva, V., Stepacheva, A. (2016). Kinetic Study of the Catalytic Pyrolysis of Oil-Containing Waste. Bulletin of Chemical Reaction Engineering \& Catalysis, 11 (3): 330-338 (doi:10.9767/bcrec.11.3.572.330-338)

Permalink/DOI: http://doi.org/10.9767/bcrec.11.3.572.330-338

\section{Introduction}

All the stages of oil production, transportation and storage as well as the synthesis of oil related products involve the formation of oilcontaining waste (oil-slime), that is one of the most hazardous pollutants of surface and ground water, terrain and atmospheric air [1]. The world production of crude oil increases every year and amounts 49 billion tons per year. The contribution of the Russian Federation to the global oil recovery budget is about 500 million tons per year, besides the amount of the produced oil-containing waste can reach up to $10 \%$ of the total volume of the produced oil $[2,3]$. The oil-containing waste can be ob-

* Corresponding Author.

E-mail: sulman@online.tver.ru (E. Sulman)

Tel: +74-822-449348, Fax: +74-822-449317 tained at all the stages of processing, storage, transportation and the use of oil. It also requires a large area for the earthen containers and sludge collectors, resulting in the energy carrier price rise. The significant pollution of the environment is the result of oil spill, waste disposal, and oil waste burning or dumping; that leads to the significant deterioration of the living conditions [3-7]. Even more, annually thousands of tons of oil-slime are stored in sludge tanks demonstrating ineffective use of fossil fuel, and the storage of oil-containing waste in sludge tanks endangers the environment [3]. Oil-containing waste mainly consists of heavy and residual hydrocarbons of the oilproducts, water and mineral components (sand, clay, metals oxides etc.) which account for their variable composition and complicate their disposal [5]. This is the reason for the development of the green and ecologically friendly 
technology for oil waste processing mainly to the energy [6].

The existing methods of oil-containing waste processing can be divided into physical, chemical, physicochemical, thermal and biological $[8$, 9]. The choice of the method of oil-containing waste processing and decontamination mostly depends on the amount and nature of oilproducts in oil-containing waste. The methods of oil-containing waste processing used in industry are quite expensive and time consuming, so the volume of oil-containing waste processing is much lower than the volume of its formation [8]. The thermal treatment resulting in gaseous and liquid fuel formation is considered to be the most economically beneficial [9-10]. Besides oil waste sensible utilization can be an essential step towards the development of resource-saving technology on the basis of the integrated use of oil raw material.

Thus, a non-catalytic pyrolysis of oilcontaining waste was studied for many years [11-14], but many disadvantages, such as high energy intensity made this process unfavorable. The use of the catalysts in the pyrolysis process of oil-slime allows obtaining products which can be used either as fuel or raw material for the chemical industry [9-10]. Compared to other methods of oil-containing waste thermal treatment, the catalytic pyrolysis has a number of advantages: (i) rather low process temperature $\left(400-650^{\circ} \mathrm{C}\right.$ ), (ii) low sensitivity to the feedstock composition and (iii) a closed circuit of processing that comply with the modern requirements of chemical production. Furthermore, the use of the catalysts in the pyrolysis process allows increasing the yield and quality of valuable products and increasing the calorific value of the gaseous products [1517]. The practical application of the catalytic pyrolysis method will contribute to the solution of the problem of oil waste disposal and thus to the development of thermal catalytic processing of organic waste with obtaining valuable final products. Catalytic pyrolysis of a number of organic compounds (wood, polymers, and hydrocarbons) has been recently studied using metal chlorides as catalysts [18-20]. However, no catalytic studies of metal chlorides in the pyrolysis of oil-containing waste have been published.

This paper focuses on the investigation of the influence of metal chlorides on catalytic pyrolysis of oil-containing waste. We demonstrate that the highest conversion of oilcontaining waste into gaseous and liquid products was observed in the presence of iron subgroup metal chlorides, in particular $\mathrm{CoCl}_{2}$.
The substantial increase of the conversion into gaseous and liquid products for this metal salt indicates that the catalytic pyrolysis of oilcontaining waste is promising for the industrial application.

\section{Materials and Method}

\subsection{Materials}

The chemical grade cobalt chloride $\mathrm{CoCl}_{2} \cdot 6 \mathrm{H}_{2} \mathrm{O}$ was purchased from Reakhim (Moscow) and used as received.

Model oil-containing waste was prepared from silica sand (fraction 0.1-0.4 mm, Voronezh Region oil field, Russian Federation) and from oil from the Caspian field at various weight ratios. The oil used possessed the following characteristics presented in Table 1.

\subsection{Procedure of the pyrolysis}

The pyrolysis process was carried out with an experimental pyrolysis set-up in a temperature range from 450 to $650{ }^{\circ} \mathrm{C}$. The experimental pyrolysis set-up consists of a metal fixed-bed reactor heated with the electric furnace, a gas sampler, a water trap for collecting liquids, and a eudiometer for collecting gas (Figure 1). The reactor was equipped with an outlet for inert-gas purging. The process of slow pyrolysis was performed in nitrogen during 96 minutes. The blow off with inert gas was carried out before the experiment. The weight of the oil-containing waste studied was varied depending on the oil fraction concentration. Oil fraction weight was constant $(2 \mathrm{~g})$. The oil-fraction content in oilcontaining waste varied from 10 up to $100 \%$ (wt.) due to the change of mineral fraction weight. $\mathrm{CoCl}_{2}$ catalyst content of oil-containing waste was from 1 up to $10 \%$ (wt.) of the oilfraction weight. The catalyst was introduced into the oil-containing waste in the form of a solid salt. The duration of the experiment was an hour and a half. Each procedure was repeated at least three times to insure reproducibility of the results.

\subsection{Reaction mixture analysis}

After completion of the experiment, the following parameters were determined: solid residue weight according to the change of the reactor weight; liquid fraction weight according to water trap and sampler weight; gas weight according to the difference of the initial sample, liquid and solid residue weight. Standard deviation for the pyrolysis products is $\pm 0.5 \%$ (wt.) from weight measurements. In order to analyze 
the composition (hydrocarbons, $\mathrm{CO}, \mathrm{CO}_{2}, \mathrm{H}_{2}$ ) and to estimate the heat capacity of the gaseous mixture, the state-of-the-art analytic complex including gas chromatographs (Crystallux 4000M, GAZOKHROM 2000) and a specially developed analyzer of the specific heat of combustion on the base of a flame-temperature detector, were used. The chromatographic analysis of hydrocarbons in the gaseous mixture was carried out on the chromatograph Crystallux $4000 \mathrm{M}$ under the following conditions: the consumption of gas-carrier (nitrogen) $120 \mathrm{~mL} / \mathrm{min}$; gas-carrier pressure $1.5 \mathrm{~kg} . \mathrm{s} / \mathrm{cm}^{3}$; duration of the analysis $30 \mathrm{~min}$; sample volume $1 \mathrm{~mL}$; carrier-silica gel $0.4 \mathrm{~mm}$; column length $1 \mathrm{~m}$; column temperature $50{ }^{\circ} \mathrm{C}$; detector temperature $100{ }^{\circ} \mathrm{C}$. Volume concentrations of nitrogen, carbon oxides and methane were analyzed on the chromatograph GAZOKHROM 2000. The flow rate of the gascarrier (helium) was $30 \mathrm{~cm}^{3} / \mathrm{min}$; the sample volume of the gas analysed was $0.5 \mathrm{~cm}^{3}$; the thermostat temperature was $40^{\circ} \mathrm{C}$.

\subsection{Characterization}

The study of the kinetics of the oil sludge pyrolysis process was carried out using the thermoscales TG 209 F1 (NETZSCH) with different heating rate $\left(1,5,10,15\right.$ and $\left.20^{\circ} \mathrm{C} / \mathrm{min}\right)$. The oil-containing waste samples with the amount of crude oil 20\% (wt.) without a catalyst and with $5 \%$ (wt.) $\mathrm{CoCl}_{2}$ were used for the analysis.

The analysis conditions were as follows. The sample was heated from 30 up to $500{ }^{\circ} \mathrm{C}$ at a heating rate $1,5,10,15$ or $20^{\circ} \mathrm{C} / \mathrm{min}$ with the following $2 \mathrm{~h}$ hold at a temperature of $500{ }^{\circ} \mathrm{C}$, and then it was heated up to $600{ }^{\circ} \mathrm{C}$ at the same rate. The analysis was carried out in argon at a gas rate of $20 \mathrm{~mL} / \mathrm{min}$.

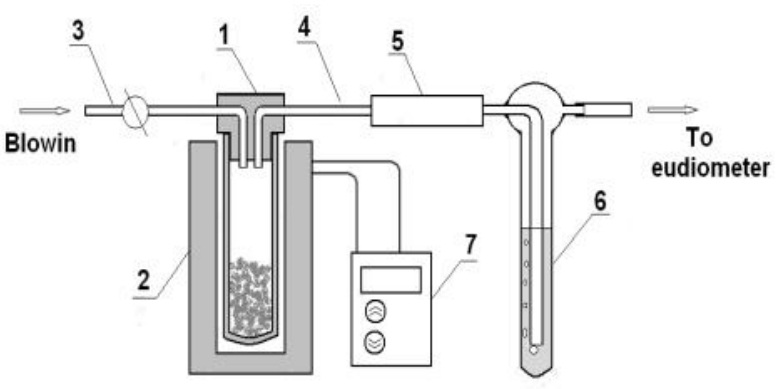

Figure 1. Scheme of pyrolysis experimental settlement: 1 - reactor; 2 - heater; 3,4 - fitting; 5 sampler; 6 - hydraulic lock; 7 - heat controller
The mathematical analysis of the experimental data on the thermogravimetric analysis (TGA) of the oil waste pyrolysis process was done using the program software "NETZSCH Thermokinetics 3.1" according to the model-independent methods of Friedman (differential method) and Ozawa-Flynn-Wall (integral method) [21], based on the isoconversion approach, when the reaction rate $d a / d t$ at some degree of conversion is only the function of the temperature (Equation (1)).

$$
\frac{d \alpha}{d t}=A \cdot \exp \left(-\frac{E}{R T}\right) \cdot f(\alpha)
$$

where $A$ is pre-exponential factor, $E$ is activation energy, $R$ is gaseous constant, and $T$ is temperature.

To determine the kinetic model of the destruction process, the non-linear regression mode was used [22-24]. The non-linear regression allows the performance of the direct approximation to the experimental data without the transformations which change the errors structure. The regression value is calculated by the quintic method of RungeKutta with the use of embedded formula of Prince-Dormand for the automatic optimization of the quantity of significant figures. To minimise the deviation and its sum of squares the upgrade version of hybrid procedure was used [25]. The statistical comparison of different models was done using $F$-test where the requirement $F_{\text {exp }}<F_{\text {crit }}$ must be valid, $F_{\text {exp }}$ $F$-test, $F_{\text {crit }}$ is statistical fractal.

The metal content was determined by X-ray fluorescence analysis (XFA) measurements performed with a Spectroscan - Maks - GF1E spectrometer (Spectron, St-Petersburg, Russia) equipped with Mo anode, LiF crystal analyzer and SZ detector. The analyses were based on the $\mathrm{Co} \mathrm{K} a$ line.

Table 1. Oil initial characteristics

\begin{tabular}{lc}
\hline \multicolumn{1}{c}{ Parameter } & Value \\
\hline density (at $20^{\circ} \mathrm{C}$ ), $\mathrm{kg} / \mathrm{m}^{3}$ & $860 \pm 2$ \\
dynamic viscosity (at $20^{\circ} \mathrm{C}$ ), $\mathrm{MPa} \cdot \mathrm{s}$ & 3.39 \\
sulphur content, \% (wt.) & 0.16 \\
paraffin content, \% (wt.) & 20.04 \\
tar content, \% (wt.) & 5.2 \\
asphaltene content, \% (wt.) & 0.94 \\
fraction yield (according to the true & \\
boiling point), \% (wt.) & \\
up to $200^{\circ} \mathrm{C}$ & 19.0 \\
up to $360^{\circ} \mathrm{C}$ & 45.0 \\
\hline
\end{tabular}




\section{Results and Discussion}

\subsection{Influence of oil-containing waste com- position and the process temperature on the products yield in the non-catalytic process}

First, the non-catalytic pyrolysis with oilcontaining waste containing $20 \%$ (wt.) of oil was studied. The pyrolysis temperature was varied between 450 and $650{ }^{\circ} \mathrm{C}$. Figure 2 shows that below $500{ }^{\circ} \mathrm{C}$, the product contains a high fraction of solid residue. At $500-550{ }^{\circ} \mathrm{C}$ high conversion of oil-containing waste into gaseous and liquid products is achieved. The increase in the process temperature from 550 to $650{ }^{\circ} \mathrm{C}$ results in the $8 \%$ increase of conversion, however, this temperature increase requires additional energy, making it economically unfavorable. Thus, 500-550 ${ }^{\circ} \mathrm{C}$ can be considered as optimal pyrolysis temperatures.

Oil-containing waste contains mineral components such as silica and small amounts of metals such as $\mathrm{Fe}$ and $\mathrm{Cu}$, which were detected by of XFA (Table 2). Apparently, trace amounts of these metals come either from sand, or from oil. On the other hand, mineral components containing more than 90\% (wt.) of $\mathrm{SiO}_{2}$ of oil-containing waste can play the role of a heat carrier that increases heat conductivity of the system and accelerates thermal degradation (heat conductivity coefficient of $\mathrm{SiO}_{2}$ (0\% humidity) is $0.33 \mathrm{~W} / \mathrm{m} \cdot \mathrm{K}$, while for oil (an average value), it is $0.13 \mathrm{~W} / \mathrm{m} \cdot \mathrm{K}$ [27]. It results, mainly, in the increase in the gaseous product yield due to the increase of the sample heating rate as is demonstrated in Figure 3. The highest yield of the gaseous and solid products was observed in the pyrolysis of the mixture containing $10-20 \%$ (wt.) of the oil fraction.

The increase in the solid residue yield can be attributed to the increase in the dehydrogenation reaction rate and the formation of unsaturated hydrocarbons contributing to coking [26]. To increase the yield of the gaseous products $\mathrm{CoCl}_{2}$ was chosen as the catalyst due to its high efficiency as it was described in the earlier works [28].

\subsection{Influence of the cobalt chloride con- tent on oil-containing waste pyrolysis}

Considering that the use of cobalt chloride resulted in the highest degree of oil-containing waste conversion into liquid and gaseous products, the influence of the catalyst content on the weight distribution of the pyrolysis products was studied with this catalyst. The results of the influence of the catalyst concentration on oil-containing waste conversion are presented in Figure 4.

Upon the addition of $2 \%$ (wt.) of cobalt chloride no changes were observed in the amount of liquid and gaseous products. The introduction of $5 \%$ (wt.) of $\mathrm{CoCl}_{2}$ increased the amount of liquid and gaseous products by $15 \%$ compared to the non-catalytic process. The further increase in $\mathrm{CoCl}_{2}$ content from 5 to $15 \%$ leads to a small decrease of the solid residue weight and therefore to the small increase in the amount of liquid and gaseous products. This is explained by the loss of crystallization water from the crystal hydrate. Based on the above, the optimal content of the catalyst is $5 \%$ (wt.) of the oil fraction weight.

\subsection{The kinetic study of the oil-containing waste pyrolysis process by thermogravim- etry method}

As it was noted above the use of $\mathrm{CoCl}_{2}$ as the catalyst in pyrolysis process allows decreasing the temperature and increasing of gaseous product yield while the process conducting in reactor. Thermogravimetric analysis of oilcontaining substrate in the presence of cobalt chloride also showed the decrease of solid residue mass that indicated the light product formation, as well as the decrease of maximal weight loss temperature pointing to the thermodestruction temperature reduction.

The oil-containing waste pyrolysis is the complex process consisting of numerous chemical reactions, so the study of the mechanism of a singular stage is a difficult task. Depending on the chemical composition of oil sludge, reaction medium, the catalyst presence and the process temperature, various reactions of destruction proceed. Therefore the reaction order and kinetic parameters of Arrhenius equation are the conditional characteristics that show the sum of various chemical processes and are named the apparent parameters.

The curves of the function $(\log d a / d t)=f^{*}(1 / T)$ (Figures $5 \mathrm{a}$ and $5 \mathrm{~b}$ ) were plotted basing on the weight loss of the samples of oil-containing waste at different heating rates. In accordance to the given curves, the slope of the lines directly-proportional to the activation energy changes with the increase of the conversion; this can testify the proceeding of the multi-stage pyrolysis process both non-catalytically and in the presence of cobalt chloride.

In the case of the multi-stage process using Friedman method the information can be obtained only for the initial field. In Figures $6 a$ and $6 \mathrm{~b}$ the dependences of the logarithm of the 
Table 2. Oil-containing waste elemental analysis

\begin{tabular}{lccccc}
\hline \multirow{2}{*}{ Solid residue } & \multicolumn{3}{c}{ Determined element, \% (wt) } & Undetermined component, \\
\cline { 2 - 5 } & Silica $\left(\mathrm{SiO}_{2}\right)$ & $\mathrm{Fe}$ & $\mathrm{Cu}$ & $\mathrm{Co}$ & \% (wt) \\
\hline Initial component & 99.93 & 0.02 & 0.04 & - & - \\
Without a catalyst $450{ }^{\circ} \mathrm{C}$ & 87.88 & 0.04 & 0.03 & - & 12 \\
Without a catalyst $500{ }^{\circ} \mathrm{C}$ & 94.74 & 0.03 & 0.03 & - & 5.2 \\
Without a catalyst $600{ }^{\circ} \mathrm{C}$ & 96.15 & 0.02 & 0.03 & - & 3.8 \\
Catalyst $\mathrm{CoCl}_{2} 500^{\circ} \mathrm{C}$ & 96.13 & 0.06 & 0.04 & 0.57 & 3.2 \\
\hline
\end{tabular}

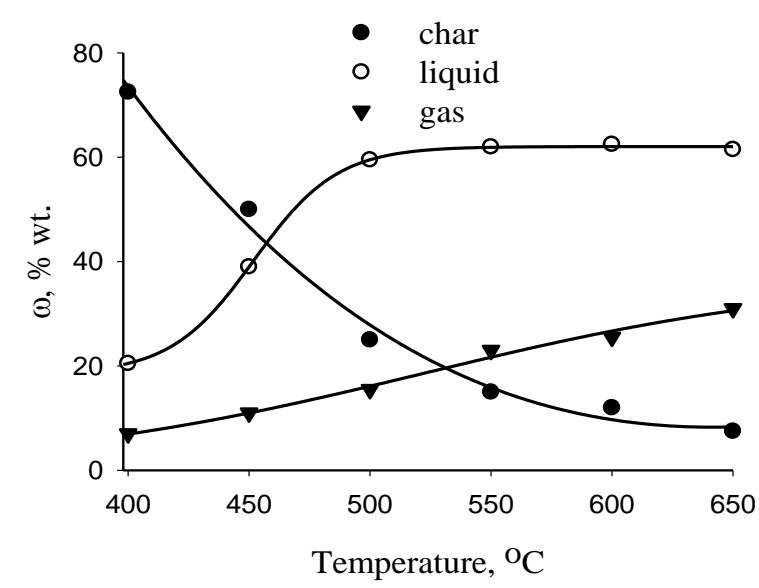

Figure 2. Pyrolysis products weight percent dependence on the process temperature

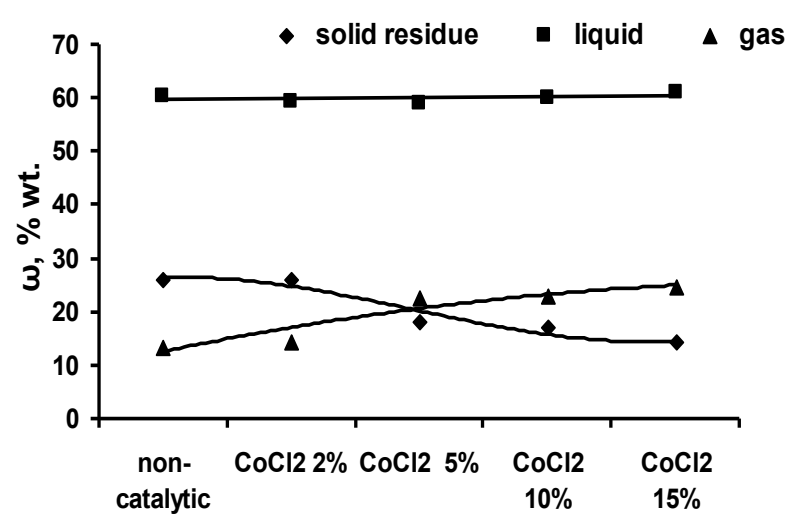

Figure 4. Influence of the catalyst content on the pyrolysis products weight percent

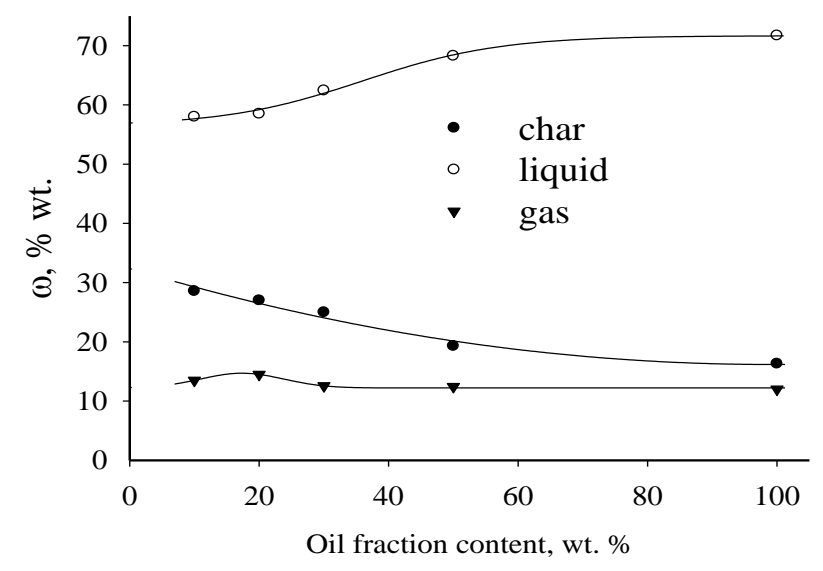

Figure 3. Pyrolysis products weight percent dependence on oil fraction content
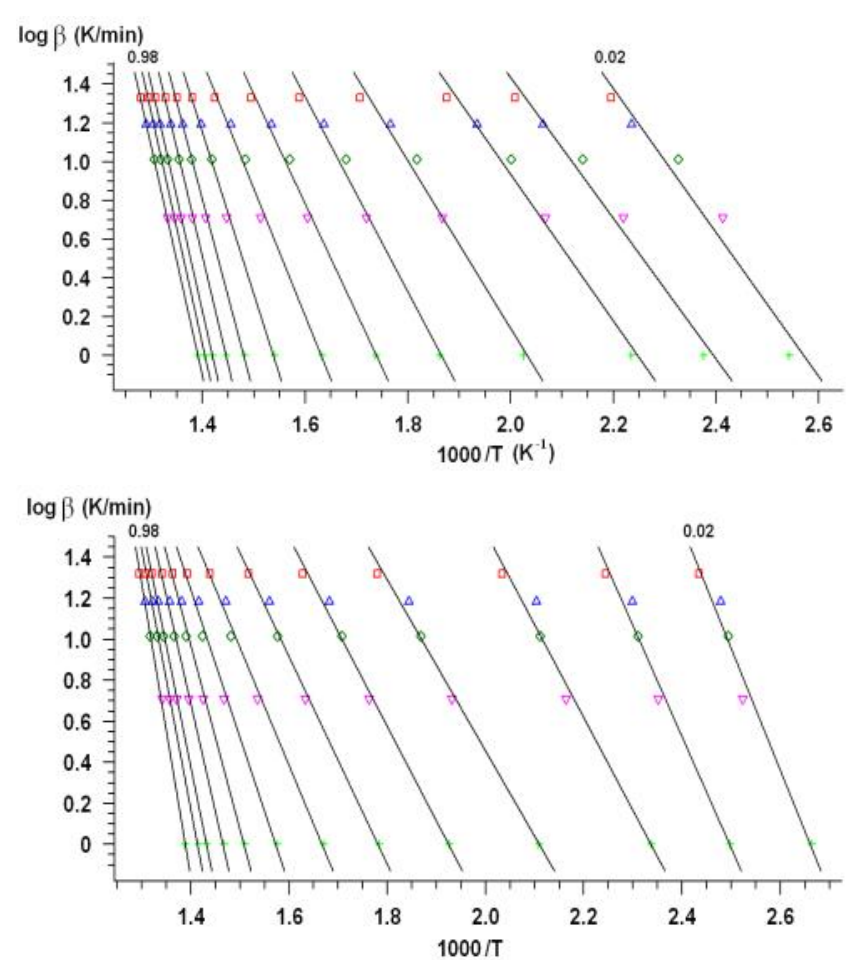

Figure 5. The samples weight loss rates in the coordinates log da/dt-1000/T, obtained using Ozawa-Flynn-Wall method: a - non catalytic; b with $\mathrm{CoCl}_{2} 5 \%$ (wt.) 
samples destruction rate on the reciprocal temperature are shown. The lines connecting the experimental points in the range $0.02 \leq a \leq 0.1$ have minor angle of the slope to the $\mathrm{x}$-axis than the lines of isoconversion and, hence, the initial destruction can be described as diffusioncontrolled reaction both in the case of noncatalytic and catalytic process.

On the base of isoconversion curves (Figures 5 and 6) the value of the activation energy and the logarithm of pre-exponential factor were calculated using Friedman and Ozawa-FlynnWall methods. The values of kinetic parameters of the Arrhenius equation obtained by two methods are in high convergence. In Figures $7 \mathrm{a}$ and $7 \mathrm{~b}$ the kinetic parameters of both non-catalytic and catalytic oil-containing waste pyrolysis are shown. According to the curves the process activation energy depends on the conversion $a$, this fact verifies the hypothesis on the multi-stage process.

Analyzing the data (Figures $7 \mathrm{a}$ and $7 \mathrm{~b}$ ), one can suppose that the non-catalytic pyrolysis process of oil-containing waste passes through two stages because the minimum and the maximum of the activation energies at the conversion 0.5 and 0.9 respectively can be defined. In the case of catalytic process,
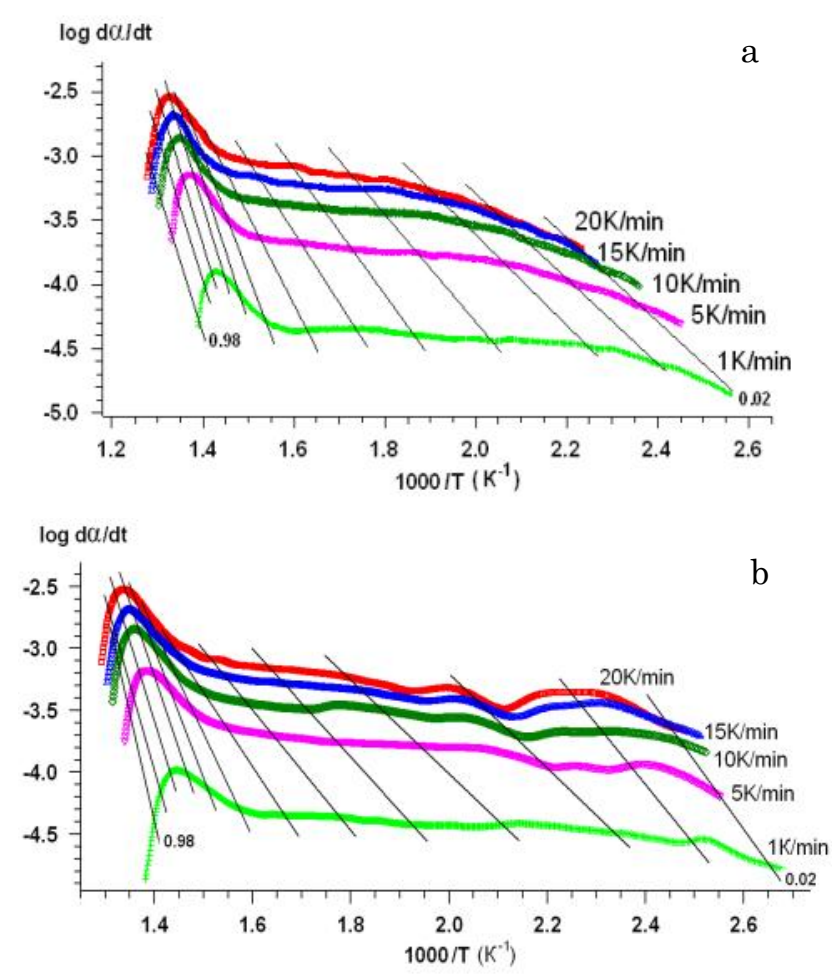

Figure 6. The samples weight loss rate in the coordinates log $d a / d t-1000 / T$, obtained using Friedman method: a - non catalytic; b with $\mathrm{CoCl}_{2} 5 \%$ (wt.) pyrolysis can pass through three stages. It can be explained by the observation of two minima of activation energy at the conversion 0.2 and 0.5 respectively, and at the conversion close to 1.0 the activation energy value essentially increases and reaches up to $235 \mathrm{~kJ} / \mathrm{mol}$.

A number of kinetic models were tested taking into account the data of isoconversion analysis methods. The statistical analysis on the base of $F$-test showed the prevalence of one kinetic model to describe both the non-catalytic and catalytic oil sludge pyrolysis that satisfies the condition of $F_{\text {exp }} \leq F_{\text {crit }}$ with the value of significance $95 \%$. According to the obtained models, the non-catalytic pyrolysis process consists of three stages and the catalytic process passes through four stages (Figures 8a and $8 b)$.

The kinetic parameters are shown in Table 3. It is noteworthy that the obtained kinetic models have a formal character and the chemism of the oil slime pyrolysis process cannot be described only on the base of TGA data. The statistical analysis of the obtained kinetic parameters of both non-catalytic and catalytic pyrolyses of oil-containing waste is shown in Table 4.
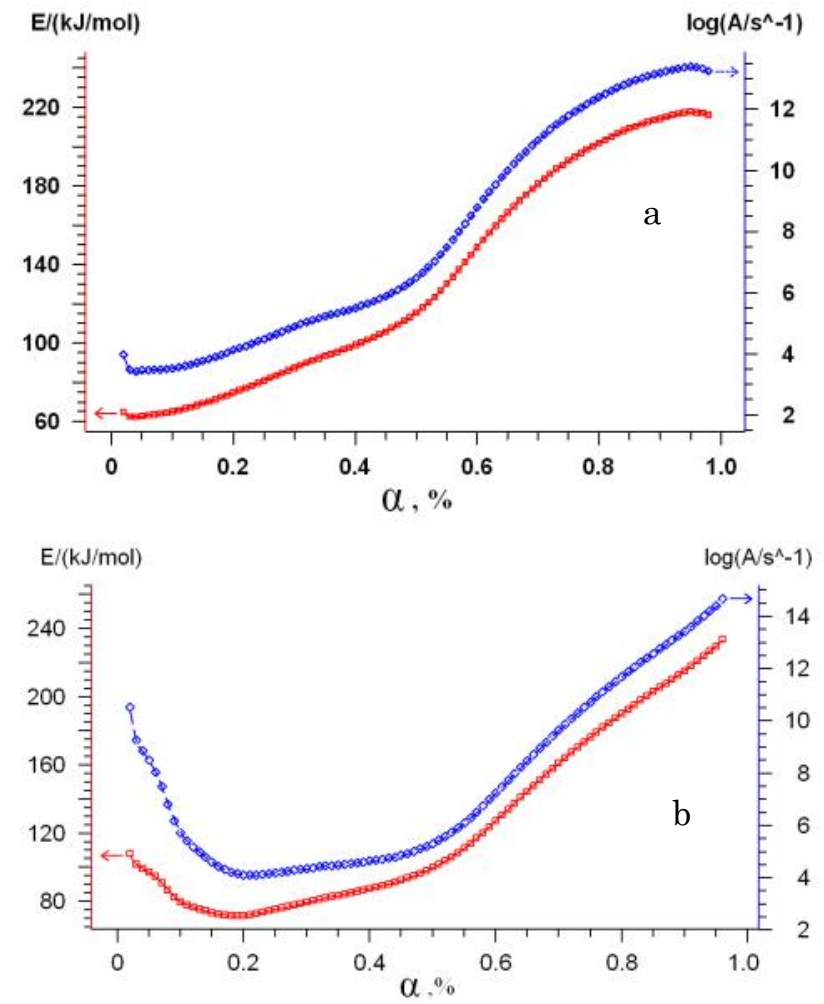

Figure 7. The activation energy and logarithm of the pre-exponential factor dependence on the sample partial weight loss obtained using Ozawa-Flynn-Wall method: a - non catalytic; b - with $\mathrm{CoCl}_{2} 5 \%$ (wt.) 
According to the data (Table 3), the use of $\mathrm{CoCl}_{2}$ in the oil-containing waste pyrolysis process leads to the decrease of apparent activation energy of thermodestruction process in the two last stages approximately by 10 and $20 \mathrm{~kJ} / \mathrm{mol}$, respectively, as well as to the change of the reaction order that can be induced by the catalysis of the destruction process by $\mathrm{CoCl}_{2}$.

\section{Conclusions}

The study showed that the catalytic pyrolysis of oil-containing waste allows obtaining the combustible gas and liquid with a high calorific value that opens the possibility of using catalytic pyrolysis in the field of alternative energy production and ecology problem solution. It was founded that the use of cobalt chloride in heavy and residual hydrocarbon pyrolysis allows decreasing the process temperature and increasing the yield of valuable product such as combustible gases an pyrolisis liquid. The optimal parameters of the catalytic oil-containing waste pyrolysis process were defined as following: the process temperature of $500{ }^{\circ} \mathrm{C}$, the oil fraction content of $10-20 \%$, catalyst of $\mathrm{CoCl}_{2} \cdot 6 \mathrm{H}_{2} \mathrm{O}$, and $5 \%$ (wt.) of cobalt chloride of the oil-containing waste oil fraction weight. Basing on the kinetic investigation it was founded that the use of $\mathrm{CoCl}_{2}$ in the oil-containing waste pyrolysis process leads to the change of the destruction mechanism and to the decrease in the process activation energy by $10-20 \mathrm{~kJ} / \mathrm{mol}$ and reaches $235 \mathrm{~kJ} / \mathrm{mol}$.

\section{Acknowledgement}

The authors thank the Ministry of Education and Science of the Russian Federation (project RFMEFI57714X0149) and Russian Foundation for Basic Research for the financial support.

Table 4. The statistical analysis of kinetic parameters

\begin{tabular}{lcc}
\hline Parameter & $\begin{array}{c}\text { non cata- } \\
\text { lytic }\end{array}$ & $\begin{array}{c}\mathrm{CoCl}_{2} 5 \% \\
\text { (wt.) }\end{array}$ \\
\hline Sum of least squares & $2.71 \times 10^{-2}$ & $3.95 \times 10^{-2}$ \\
Correlation coefficient & 0.999625 & 0.999561 \\
Standard deviation & $2.96 \times 10^{-3}$ & $3.59 \times 10^{-3}$ \\
\hline
\end{tabular}
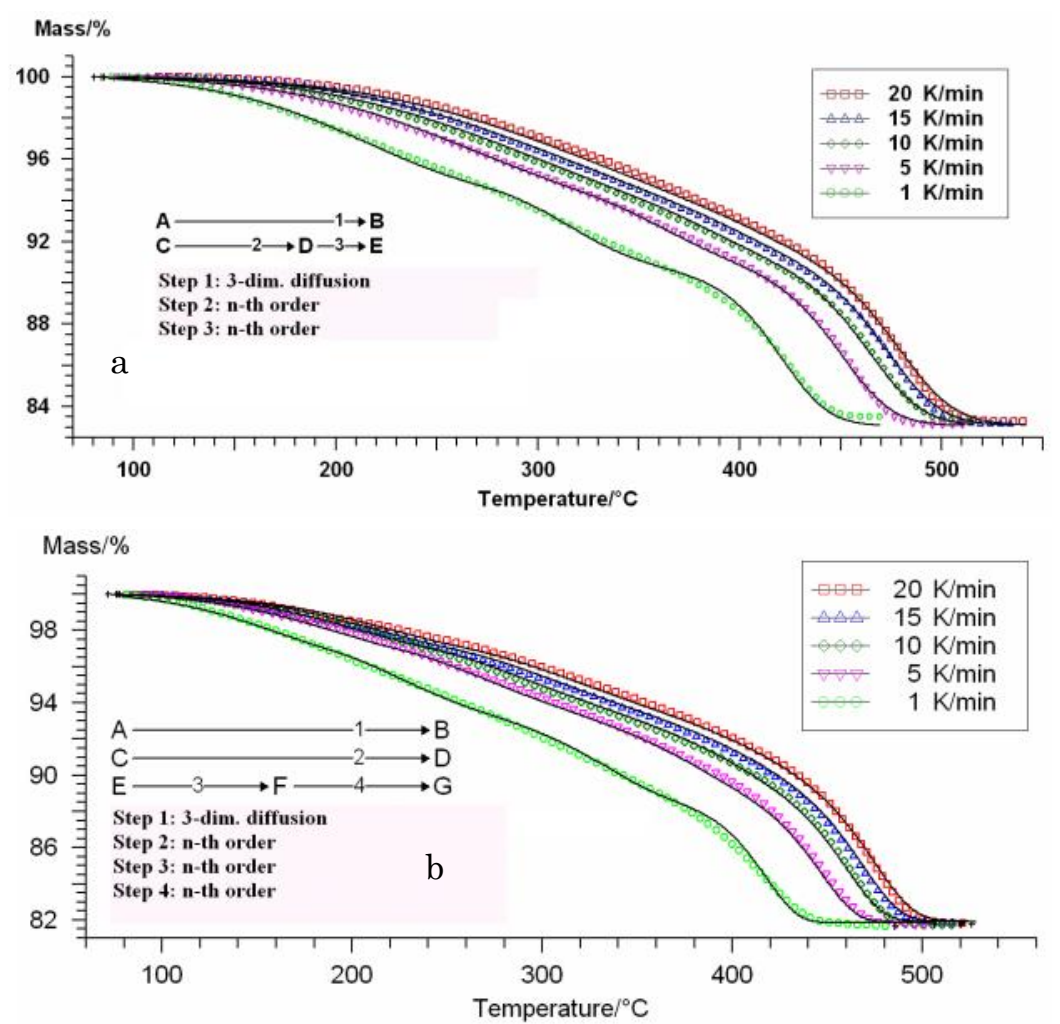

Figure 8. The weight loss of oil-containing waste samples at different heating rates K/min: 1, 5, 10, 15 , 20; a - non catalytic; b - with $\mathrm{CoCl}_{2} 5 \%$ (wt.) 


\section{References}

[1] Wang, Z., Guo, Q., Liu, X., Cao, C. (2007). Low Temperature Pyrolysis Characteristics of Oil Sludge under Various Heating Conditions. Energy Fuels, 21: 957-962.

[2] Kurochkin, A.K., Tamm, T. (2010). Oil slime resource raw materials for production of light motor fuels and road bitumens. Sphere petrogas, 4: 72-81.

[3] Kuriakose, A.P., Manjooran, S.K.B. (1994). Utilization of refinery sludge for lighter oils and industrial bitumen. Energy Fuels, 8: 788792 .

[4] Shie, J.-L., Lin, J.-P., Chang, C.-Y., Lee, D.-J., Wud, C.-H. (2003). Pyrolysis of oil sludge with additives of sodium and potassium compounds. Resour. Conserv. Recycl., 39: 51-64.

[5] Bokovikova, T. N., Shperber, E. R., Shperber, D. R. (2011). Elaboration of application methods for trice oil emulsions and oil-slimes. NAFTA. 62 (7-8): 253-256.

[6] Shie, J.-L., Chang, C.-Y., Lin, J.-P., Lee, D.-J., Wu, C.-H. (2002) Use of Inexpensive Additives in Pyrolysis of Oil Sludge. Energy Fuels. 16: $102-108$

[7] Rasul, M.G., Jahirul, M.I. (2012) Recent Developments in Biomass Pyrolysis for Bio-Fuel Production: Its Potential for Commercial Applications. Recent Researches in Environmental and Geological Sciences. 256-265

[8] Bokovikova, T.N., Shperber, D.R., Shperber, E.R. (2011). Application of oil-slimes in road base and surface construction. NAFTA. 62 (11-12): 383-385.

[9] Shie, J.-L., Chang, C.-Y., Lin, J.-P., Wu, C.H., Lee, D.-J. (2000). Resources recovery of oil sludge by pyrolysis: kinetics study. J. Chem. Technol. Biotechnol. 75: 443-450.

[10] Karayildirim, T., Yanik, J., Yuksel, M., Bockhorn, H. (2006). Characterisation of products from pyrolysis of waste sludges. Fuel. 85: 1498-1508.

[11] Shie, J.-L., Chang, Ch.-Y., Lin, J.-P., Wu, Ch.H., Lee, D.-J. (2000). Resources recovery of oil sludge by pyrolysis: kinetics study. J. Chem. Technol. Biotechnol. 75: 443-450.

[12] Fonts, I., Kuoppala, E., Oasmaa, A. (2009). Physicochemical Properties of Product Liquid from Pyrolysis of Sewage Sludge. Energy Fuels. 23: 4121-4128.

[13] Karayildirim, T., Yanik, J., Yuksel, M., Bockhorn, H. (2006). Characterisation of products from pyrolysis of waste sludges. Fuel. 85: 1498-1508.
[14] Rulkens, W. (2008). Sewage Sludge as a Biomass Resource for the Production of Energy: Overview and Assessment of the Various Options. Energy Fuels. 22(1): 9-15.

[15] Kaminsky, W., Zorriqueta, I.-J. N. (2007). Catalytical and thermal pyrolysis of polyolefins. J. of Anal. Appl. Pyrol. 79(1-2): 368-374.

[16] Sulman, M., Kosivtsov, Yu., Sulman, E., Alfyorov, V., Lugovoy, Yu., Molchanov, V., Tyamina, I., Misnikov, O., Afanasjev, A., Kumar, N., Murzin, D. (2009). Influence of aluminosilicate materials on the peat lowtemperature pyrolysis and gas formation. Chem. Eng. J. 154: 355-360.

[17] Zou, X., Yao, J., Yang, X., Song, W., Lin, W. (2007). Catalytic Effects of Metal Chlorides on the Pyrolysis of Lignite. Energy Fuels. 21: 619-624.

[18] Blasi, C.D., Branca, C., Galgano, A. (2008). Products and Global Weight Loss Rates of Wood Decomposition Catalyzed by Zinc Chloride. Energy Fuels. 22(1): 663-670.

[19] Junwon, J., Jinhwan, K., Jin-Young B. (2005). Effects of Lewis acid-type transition metal chloride additives on the thermal degradation of ABS. Polym. Degrad. Stab. 88(2): 324-332.

[20] Shilina M.I., Bakharev R.V., Smirnov V.V. (2008). Aluminum halide-cobalt halide polynuclear complexes active in lowtemperature conversion of alkanes: formation, molecular structures, and IR spectra. Russ. Chem. Bull. 57(11): 2251-2260.

[21] Kaisersberger, E., Opfermann, J. (1991). Kinetic evaluation of exothermal reactions measured by DSC. Thermochimica Acta. 187: 151-158

[22] Brown, M.E., Maciejewski, M., Vyazovkin S. (2000). Computational aspects of kinetic analysis Part A: The ICTAC kinetics projectdata, method and results. Thermochimica Acta. 355(1-2): 125-143.

[23] Fillips, P.De, Caprarils, B.De, Scarella, M., Verdone, N. (2014). Double Distribution Activation Energy Model for microalgae pyrolysis. Recent Advances in Energy, Environment and Financial Planning. 68-73.

[24] Marquardt, D. (1963). An Algorithm for Least-Squares Estimation of nonlinear parameters. Journal of the Society for Industrial and Applied Mathematics. 11(2): 431441.

[25] Minsker, K.S., Ivanova, S.R., Biglova, R.Z. (1995). Complexes of metal chlorides with proton donors - promising polyfunctional catalysts for electrophilic processes. Russ. Chem. Rev. 64(5): 429-444. 
[26] Elam, S.K., Tokura, I., Saito, K. (1989). Thermal conductivity of crude oils. Exp. Therm. Fluid Sci. 2(1): 1-6.

[27] Patnaik, P. (2002) Handbook of Inorganic Chemicals. The McGraw-Hill: New York.
[28] Chalov K.V., Lugovoy Yu.V., Doluda V.Yu., Sidorov A.I., Sulman M.G., Kosivtsov Yu.Yu., Tkachenko O.P., Sulman E.M. (2014). Influence of metal chlorides on oil-slime thermocatalytic processing. Chem. Eng. J. 238: 219226. 